\title{
Dynamic simulation of urbanization and eco-environment coupling: Current knowledge and future prospects
}

\author{
CUI Xuegang ${ }^{1,2},{ }^{*}$ FANG Chuanglin ${ }^{1,2}$, LIU Haimeng ${ }^{1,2}$, LIU Xiaofei ${ }^{1,2}$, \\ LI Yonghong ${ }^{3}$ \\ 1. Institute of Geographic Sciences and Natural Resources Research, CAS, Beijing 100101, China; \\ 2. University of Chinese Academy of Sciences, Beijing 100049, China; \\ 3. Institute of Water Ecology, Beijing Orient Landscape \& Environment Co., Ltd., Beijing 100015, China
}

\begin{abstract}
Urbanization and eco-environment coupling is a research hotspot. Dynamic simulation of urbanization and eco-environment coupling needs to be improved because the processes of coupling are complex and statistical methods are limited. Systems science and cross-scale coupling allow us to define the coupled urbanization and eco-environment system as an open complex giant system with multiple feedback loops. We review the current state of dynamic simulation of urbanization and eco-environment coupling and find that: (1) The use of dynamic simulation is an increasing trend, the relevant theory is being developed, and modeling processes are being improved; (2) Dynamic simulation technology has become diversified, refined, intelligent and integrated; (3) Simulation is mainly performed for three aspects of the coupling, multiple regions and multiple elements, local coupling and telecoupling, and regional synergy. However, we also found some shortcomings: (1) Basic theories are inadequately developed and insufficiently integrated; (2) The methods of unifying systems and sharing data are behind the times; (3) Coupling relations and the dynamic characteristics of the main driving elements are not fully understood or completely identified. Additionally, simulation of telecoupling does not quantify parameters and is not systemically unified, and therefore cannot be used to represent spatial synergy. In the future, we must promote communication between research networks, technology integration and data sharing to identify the processes governing change in coupled relations and in the main driving elements in urban agglomerations. Finally, we must build decision support systems to plan and ensure regional sustainable urbanization.
\end{abstract}

Keywords: urbanization and eco-environment coupling; dynamic simulation; theory; methods; applications

\section{Introduction}

Urbanization drives environmental change on many scales, fundamentally changing regional landscapes and their ecology (Tratalos et al., 2007; Grimm et al., 2008). The International

Received: 2019-08-29 Accepted: 2019-10-18

Foundation: Major Program of National Natural Science Foundation of China, No.41590840, No.41590842

Author: Cui Xuegang (1990-), PhD, specialized in urban geography and regional planning. E-mail: cuixg.16b@igsnrr.ac.cn

"Corresponding author: Fang Chuanglin (1966-), PhD and Professor. E-mail: fangcl@igsnrr.ac.cn 
Council for Science (ICSU) and the International Social Science Council (ISSC) launched the Future Earth initiative, which listed the Urbanization and Global Environmental Change Project (UGEC) as a core research project to study global environmental changes caused by urbanization (Li et al., 2008; Xie et al., 2010; Sanchez-Rodriguez et al., 2014). Research has shown that urban expansion determines landscape patterns, thus affecting land use and land cover change (LUCC), biodiversity, and hydrology. Waste and emissions during urbanization also affect the global climate and biogeochemical cycles (Chen et al., 2013; Schneider et al., 2015).

Urbanization in China ignores resource and environmental constraints (Fang, 2009). Urbanization in China has resulted in the loss of cultivated land, resource shortages, habitat fragmentation, and $\mathrm{PM}_{2.5}$ pollution (Li et al., 2009; Zhou et al., 2014; Cui et al., 2016). Air and water pollution and other environmental problems are especially concentrated in urban agglomerations (Fang et al., 2010; Wang et al., 2014; Wang, 2017). Many researchers are interested in urbanization and eco-environment coupling because of their awareness of international developments in earth science and sustainability as well as their knowledge of the current state of urbanization in China (Kates et al., 2001; Reid et al., 2010; Fang et al., 2017). There is a multifaceted nonlinear interactive coupling relationship between urbanization and the eco-environment; therefore, the internal processes characterized by differences in stage and space, are complicated (Fang and Yang, 2006; Fang et al., 2016). Many scholars have used historical data from different regions to infer quantitative relationships that govern the coupling of urbanization and the eco-environment, and they have found that a second order polynomial or an inverted U-shaped curve is a good representation (Huang and Fang, 2003; Liu and Wang, 2015; Sun et al., 2017). The complexity of coupling relationships makes it difficult to study urbanization and eco-environment coupling within a single paradigm. A geographical study moves from knowledge description to process simulation and then to decision support (Fu, 2017). In the future, dynamic simulation of urbanization and eco-environment coupling would become an important activity.

Dynamic simulation reproduces historical geographical processes and predicts trends in their future development (Tang et al., 2010). Multi-scenario simulation of urbanization and eco-environment coupling can lead to the identification of coupling mechanisms and future trends. It also allows for optimal regulatory measures that coordinate urbanization and eco-environmental change to be selected. The successful dynamic simulation requires consistency between theory, method, and application; therefore, three key questions should be asked to ensure the consistency: (1) What are the theoretical foundations of the dynamic simulation, and what underlying regularities do these theories entail? (2) What simulation methods are available, and how accurate and applicable are they? (3) What specific applications are based on existing theories and methods, and how do these applications embody regional differences, identify the main control elements and reflect the cross-scale coupling? This paper will answer these questions by reviewing related theories, methods and applications.

\section{Progress in theoretical research on dynamic simulation of urbanization and eco-environment coupling}

Simulation is premised on the assumption that it can reveal the structure and underlying 
processes of a system. We draw on theories of systems science and cross-scale coupling to characterize the coupled urbanization and eco-environment system as an open complex system with multiple feedbacks to describe the system structure and evolution mechanism.

\subsection{Human-environment interaction}

Human-environment interaction is at the core of human geography. It originated as an object of study in the French school of geography represented by de la Blache and Brunhes (Wu, 1991). Many researchers have studied sustainable development from the perspective of human-environment interaction and the theory developed around it ( $\mathrm{Lu}$ and Guo, 1998). The theory of human-environment interaction emphasizes the objective connection between human activity and the geographical environment; thus they together constitute a complex open system that has been called the geographic system of human-environment interaction (Wu, 2008).

Urbanization is a significant human activity; in a narrow sense, the eco-environment constitutes the geographical environment. A theory of human-environment interaction is foundational to the research for urbanization and eco-environment coupling; moreover, coordinated development between urbanization and the eco-environment is an embodiment of sustainable development. As human-environment interaction becomes more intricate than before, the boundary between urbanization and the eco-environment becomes fuzzier (Fan, 2014). Human-environment interaction determines the overall stability of the system. If the extent of human activity exceeds its carrying capacity, the geographic system of human-environment interaction would collapse. Thus the geographic system of human-environment interaction should take sustainable development as a long-term goal and control development to determine policy and to promote technological growth. To ensure the sustainable development of the geographic system of human-environment interaction, we must focus on the effects of human activity on natural resources and the eco-environment (Li et al., 2016).

\subsection{Urban social-ecological system theory}

The coupled urbanization and eco-environment system is a dynamic, multidimensional and collaborative complex system; it is constituted by a set of systems which include the social-economic-natural complex ecosystem (SENCE), the composite economy-resourcesenvironment (ERE) system, and the urban ecological-economic (UEE) system (Ma and Wang, 1984; Liu et al., 2013; Fang et al., 2017).

The urban social-ecological system (USES) has been internationally recognized. Ostrom (2009) considered that a social-ecological system (SES) consists of four subsystems: the resource unit (RU), resource system (RS), governance system (GS), and user (U). The subsystems form a unity through complex interactions. USES is an adaptive system; however, its uncertainties, which significantly affect system resilience and sustainability, are caused by policies and behavior (Walker et al., 2002). USES provides a framework for the dynamic simulation of urbanization and eco-environment coupling. We can reduce the fuzziness of the relationships caused by uncertainty in the subsystems to reduce the difficulties of dynamic simulation. Because the relationships between urbanization, natural resources, and the eco-environment are direct, we can develop an urbanization-resources-environment (URE) system (Cui et al., 
2019). Figure 1 shows that URE is an open, complex and dynamic system in a particular structure and with interactive functions (Zeng et al., 2000; Xie et al., 2016).

\subsection{Complex system theory}

Complex system theory is derived from systems science and complexity science. The terms such as self-adaptability, self-organization, uncertainty, emergence, and openness are used to describe system characteristics and to explain the processes that lead to change in the uncertain system (Liu et al., 2008). Qian et al. (1990) proposed an open complex giant system;

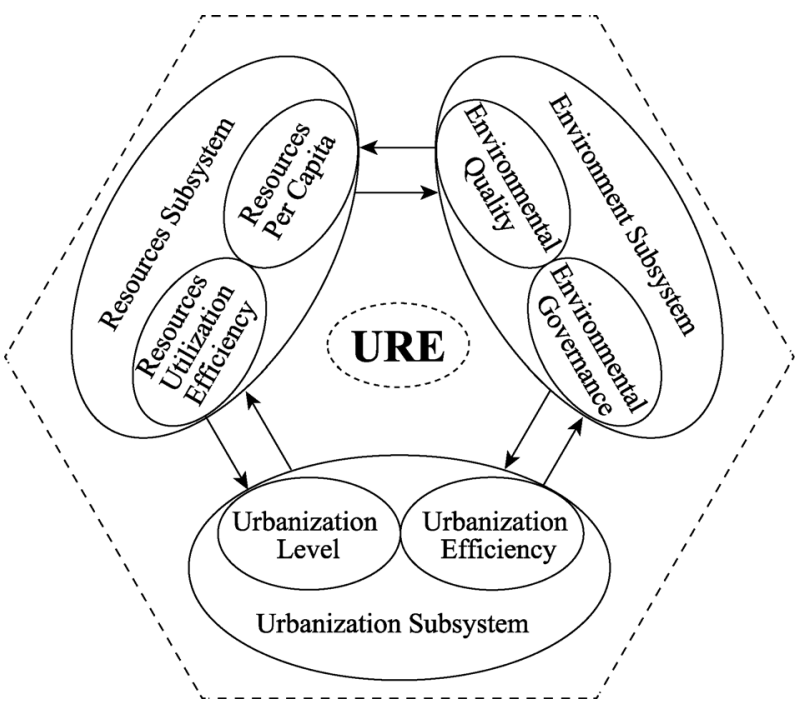

Figure 1 Interactions between urbanization, resources and environment in URE they presented that a comprehensive integration method combining qualitative and quantitative analysis was the feasible research method to simulate it.

A coupled urbanization and eco-environment system is a complex system with multiple feedback loops. The system is open and far from equilibrium (oscillating between an unsteady state and a steady state); it constantly exchanges matter, energy, and information with the outside world (Li et al., 2010). The system undergoes a process of repeated dynamic fluctuation (emergence $\rightarrow$ collaborative maintenance $\rightarrow$ critical phase change) and continuously moves towards a higher ordered state due to many self-organized changing processes such as mutual feedback of elements and energy transfer (Fang, 1989; Liu et al., 2016). A few slow-changing parameters (order parameters, which determine the order of the system) dominate the coevolution of the system (Liu et al., 2014). When change surpasses some critical point (threshold), the system produces a phase change (Dong, 2011). Urbanization, resources, and environmental factors can be regarded as order parameters, and urbanization is most important. The ultimate end of an evolving system is to change from chaos and disorder to coordination and order as it undergoes a complex series of multi-level spatio-temporal coupling processes. Though self-organization, self-adaptation, and self-learning lead to changes in system components and order parameters, the overall process of system change seems complex, dynamic, and random (Song et al., 2018).

\subsection{Coupled human and natural system theory}

At the start of the 21 st century, humans were more concerned about global environmental changes than ever before. Increased anthropogenic emissions of greenhouse gases such as $\mathrm{CO}_{2}$ had caused significant global warming; therefore, it damaged previously balanced ecosystems and endangered the safety of human social systems, leading to crises of water supply, food supply and health, and thereby posing significant challenges to sustainable development (IPCC, 2007). As a result of an essential incongruity between the cascading effects of human desires as well as goals and the balance of natural systems, humans realized that 
human activity is an important driver of global change (IGBP, 2001; Liu, 2002; Xu et al., 2013).

The processes that constitute interaction between humans and natural systems are not well understood (Liu et al., 2007). A coupled human and natural system (CHANS) was developed by Liu et al. (2007) to reveal and model multi-scale coupling mechanisms between humans and natural systems. CHANS represents complexities in organization, space, and time (Liu et al., 2007). (1) There is a nested hierarchy in the organization of the system, which is represented by direct or indirect influence and feedback loops (Allen and Starr, 1982; Gunderson et al., 2004). CHANS constitutes a complex network system that supersedes hierarchical levels through complex interactions between components (Sta et al., 2005). Characteristics of CHANS include vulnerability (Ii et al., 2003; Sven et al., 2017), critical threshold (MEA, 2005), and resilience (Holling, 1973; Jabareen, 2015). (2) There are many nested processes in CHANS, which intensify the interactions between global and local systems because of globalization, increasing population, material production, and information flow (Liu and Diamond, 2005; Lenschow et al., 2016). CHANS also shows spatial heterogeneity in urban and rural areas, where human activity damages natural systems in different ways (O'Meara, 1999; Liu et al., 2014). (3) The system drastically changes particularly in terms of population growth; therefore, it increases production and consumption which significantly increase the effects of humans on changes to the natural environment (Liu et al., 2003; Arrow et al., 2003; Entwisle and Stern, 2005). CHANS also incorporates change hysteresis (Rignot and Kanagaratnam, 2006; Bartlett, 2010). It couples human and natural systems on many scales, emphasizes the continuous change of the system in the space-time dimension, and explains the complex behavior and change processes in the coupled system.

\subsection{Telecoupling framework}

In previous studies, most attention has been paid to internal system interactions; but external influences were treated simply as external variables. However, in reality, remote interactions between systems have feedback effects. The telecoupling framework was developed to explain spatial coupling in open systems, especially remote interactions among economies, societies, and eco-environments (Liu et al., 2013; Fang and Ren, 2017).

A telecoupling framework is a multi-level framework composed of a series of CHANS. It contains five parts: system, flow, agent, cause, and effect (Liu et al., 2013). For example, Fang et al. (2016) used the telecoupling framework to analyze the impact of trade in photovoltaics between China and the European Union (EU) on energy sustainability. China forms a sending system and the EU a receiving system. China's photovoltaic exports accounted for $22.04 \%$ of the EU market share because of China's labor and environmental cost advantages and the EU's demand for photovoltaic products. As a result, China has benefited from job and tax growth, but suffered increased greenhouse gas and pollutant emissions, while the EU has mitigated climate change within its boundaries. Moreover, the coupling process between urbanization and the eco-environment exists across different spatial systems. For example, in Beijing, the high population density and a high concentration of industry result in the huge demand for water; therefore, the net volume of water imported to Beijing has increased from $3.6 \times 10^{8} \mathrm{~m}^{3}$ in 2002 to $2.9 \times 10^{9} \mathrm{~m}^{3}$ in 2012 (Sun et al., 2015). 


\subsection{Review of theoretical research}

System science theory and cross-scale coupling theory provide underlying support for dynamic simulation. The former one includes human-environment interaction theory, urban social-ecological system theory, and complex system theory; the latter one includes coupled human and natural system theory and a telecoupling framework, forming the spatio-temporal coupling model.

The coupled urbanization and eco-environment system can be regarded as an open complex giant system with multiple feedback loops; therefore, we analyze it to find the processes that determine change. (1) There are complex nonlinear relations among various elements, including one-one, one-many and many-many relations. (2) The coupling includes the telecoupling framework and distance attenuation; it could be considered as strong within the system, and loose between systems. Therefore, strong coupling often determines the direction of system change, while loose coupling cannot be ignored. In this period of globalization, telecoupling is more intensive than it used to be. (3) We must be aware of the relationships between qualitative analysis and quantitative analysis to choose a suitable dynamic simulation method. The quantitative simulation could objectively explain some natural properties and coupling regularities. However, when policies develop, using a more subjective qualitative simulation could be more effective.

Because many systems theories are not fully developed, they are often standalone or incompatible with other theories. We must continue to develop complex system theory, cross-scale coupling theory, and other new theories. Moreover, the boundaries among disciplines should be blurred to encourage interdisciplinary studies; therefore, a network to research urbanization and eco-environment coupling should be formed to optimize efforts to solve the problem of uncertainty in dynamic simulation.

\section{Progress in dynamic simulation methods of urbanization and eco-environment coupling}

Breakthroughs in computer design, artificial intelligence, GIS, and other technologies have enabled the rapid development of dynamic simulation methods. Different methods have different disciplinary backgrounds, use different algorithms, as well as possess different advantages and disadvantages. Therefore, in terms of accuracy and applicability, the results have great differences. We now summarize the context of development, conditions of application and defects of different methods and analyze how to optimize them.

\subsection{System dynamics}

System dynamics (SD) is the oldest and most commonly used dynamic simulation method. SD blends systems science and computer simulation techniques to simulate geographic systems of human-environment interaction and urban complex systems, by combining qualitative and quantitative methods (Zhong et al., 2013). The procedure for using SD is: theoretical analysis $\rightarrow$ SD modeling $\rightarrow$ dynamic simulation $\rightarrow$ scenario regulation. SD has been widely used in the dynamic simulation of urban systems, urban sustainable development, and urbanization and eco-environment multi-factor coupling. Foundational work in SD is The Limits to Growth published by the Club of Rome in 1972. The Limits to Growth simulated the coupling of the global economy, natural resources, and the eco-environment by constructing 
a world model consisting of five modules (population, agricultural production, industrial production, natural resources, and pollution); therefore, The Limits to Growth pioneered the concept of sustainable development (Meadows et al., 1972). In subsequent research, SD was used to simulate urban systems growth and sustainable development, using concepts of systemacity, complexity, coordination, and sustainability; SD was also used to define the sustainable urbanization model of coordinated development of population, economy, natural resources, and the environment (Liu et al., 2013; Fang et al., 2017). The coupling process among urbanization and natural resources, energy, greenhouse gases and geological forms was simulated on global and regional scales (Zuo, 2007; Feng et al., 2013; Yan et al., 2016).

However, the flaw of SD is that the fixed structure of the model makes it difficult to simulate systems containing uncertainties, such as technological progress, government policy and human behavior; therefore, some variable relationships are limited to being defined by the use of regression. Additionally, simulated systems tend to be macroscopic, which puts $\mathrm{SD}$ at a disadvantage when dealing with microscopic systems.

\subsection{Artificial intelligence}

Artificial intelligence (AI), in the form of artificial neural networks (ANNs) and Bayesian networks (BNs), has developed rapidly; therefore, it can at least partially solve the problem to dynamic simulation for self-organizing, self-adapting, and self-learning systems. ANN and $\mathrm{BN}$ are similar in algorithmic complexity and network training methods; but they differ in topology, learning rules, and algorithmic principles. ANN includes the use of directed acyclic graphs and directed cyclic graphs, and uses an activation function to train the model and construct the learning rules. The directed acyclic graph is commonly used by the back-propagation neural network technique with a back-propagation algorithm to train a multi-layer neural network (Haykin, 2009). However, a directed acyclic graph is used by BN; the joint distribution is decomposed into multiple probability distributions for causal inference and diagnostic inference according to the conditional independence relations among variables (Zhang and Guo, 2006; Huang, 2013). On the one hand, ANN has the advantages of self-learning, associative storage, high-speed optimization and nonlinear mapping; but it is unsuitable for causal reasoning or dealing with uncertainty (Xu, 2010). On the other hand, $\mathrm{BN}$ is suitable for causal reasoning and dealing with uncertainty problems and incomplete datasets, while its algorithm is not particularly efficient and its structured learning capacity is limited ( $\mathrm{Li}$ and Zhang, 2015). Currently, AI is mainly used to simulate urban expansion and its eco-environmental effects, to predict the demand for urban resources, and to identify sustainable management, urban ecological vulnerability as well as disaster risks (Cai et al., 2009; Froelich, 2015; Balbi et al., 2016).

There is a black box in the dynamic simulation of urbanization and eco-environment coupling, but AI could open it by deep learning. However, AI is still in the developmental stage; therefore, there is a disagreement that it is genuine intelligence rather than pseudo-intelligence. The prospect of using AI to simulate uncertain systems is appealing, and we could extend the scope of AI by embedding it in other techniques.

\subsection{Land use and land cover change model}

Land use and land cover change (LUCC) models refine the interpretation of spatial usage. 
Spatial changes in urbanization and eco-environment coupling could be shown dynamically and could be analyzed to determine how urban boundaries would expand. LUCC models include conversion of land use and its effects at small region extent (CLUE-s), cellular automata (CA) and multi-agent systems (MAS) (Deng et al., 2009). The CLUE-s model is an empirical local equilibrium model that simulates multi-scale spatial distributions of land use (Tang et al., 2009). On the one hand, CA can simulate the complex discrete changes of the local land use system by presetting the transformation rules and using a bottom-up approach. However, CA is an idealized model based on the assumption of spatial homogeneity, which makes it difficult to take account of spatial heterogeneity (Zhao et al., 2016). On the other hand, MAS includes many agents and incorporates behavior, decision-making and other factors into the processes that affect land use change; therefore, MAS can simulate changes that occur in an adaptive system better (Chen et al., 2008). However, the application of MAS is at a preliminary stage; therefore, the model is limited by the assumption of spatial homogeneity.

CLUE-s, CA and MAS simulate land urbanization and eco-environment coupling based respectively on empirical data, spatial information rules, and complex system theory; however, they are limited to the spatial perspective and must be coupled with other models to increase their applicability.

\subsection{Integrated method}

$\mathrm{SD}+$, a recently-developed combinatory method, is a bottom-up method that uses combinations of various other methods, and it has widely used (Gu et al., 2016). (1) The combination of SD with GIS is an important enhancement to the dynamic simulation of spatial change (Wan et al., 2016). (2) The combination of SD with CA is at the forefront of systems technology; therefore, it improves the interpretation of the environmental effects of urban land change (Wang et al., 2013). (3) The combination of SD with agent-based modeling (ABM) has been explored as a solution to the problems surrounding randomness, discreteness, spatial heterogeneity, and adaptability (Guerrero et al., 2013). (4) The combination of SD with CLUE-s is expected to facilitate the simulation of land use change for different urban, economic, and social development scenarios (Tian et al., 2016). In addition, Hu and Sun (2017) combined fuzzy integration, a genetic algorithm, and an artificial neural network to detect the exogenous sources that sound an alarm for regional energy security.

SD incorporates qualitative and quantitative characteristics, and it becomes an important interface for the combined systems. However, it is challenging to integrate technology and to verify the authenticity and effectiveness of existing achievements. In the future, we must combine system engineering, artificial intelligence, LUCC simulation and prediction, 3S, and other technical disciplines to build a linked dynamic simulation technology chain.

\subsection{Interactive decision support system}

To support decision-making for regional sustainable planning, researchers have developed many systems based on different objectives; researchers are longing to develop an interactive decision support system; however, the decision support systems are empirical. For example, Chen et al. (2016) designed an ecological security decision support system, which included key modules for ecological restoration and reconstruction, risk prediction and early warn- 
ing, to link and coordinate regional ecological security in the Beijing-Tianjin-Hebei urban agglomeration. Fang et al. (2017) designed an interactive decision support system for urbanization and eco-environment coupling based on multi-level, multi-scale, multi-perspective and multi-scenario optimization.

The development of an interactive interface between dynamic simulation and decision support is promoted by technology. Interactive decision support currently lacks developed products and relies on experience and judgment. In future, we must build an intelligent interactive decision support system.

\subsection{Review of dynamic simulation methods}

Dynamic simulation methods are diversified, refined, intelligent and integrated because of the use of computers, 3S and artificial intelligence. Different strengths and weaknesses of common techniques, such as SD, AI (ANN and BN) and LUCC modeling (CLUE/CLUE-s, CA and MAS), are shown in Table 1.

Table 1 Comparison of techniques for dynamic simulation of urbanization and eco-environment coupling.

\begin{tabular}{|c|c|c|c|c|}
\hline Name & Discipline & Advantages & Disadvantages & Application \\
\hline $\begin{array}{l}\text { System } \\
\text { dynamics }\end{array}$ & $\begin{array}{l}\text { Systems science } \\
\text { and computer } \\
\text { simulation }\end{array}$ & $\begin{array}{l}\text { Modeling process is } \\
\text { simple and can be com- } \\
\text { bined with an index sys- } \\
\text { tem to identify system } \\
\text { boundary and related } \\
\text { variables }\end{array}$ & $\begin{array}{l}\text { Difficult to reflect the } \\
\text { characteristics of adap- } \\
\text { tive and spatial change } \\
\text { in the system, and the } \\
\text { feedbacks are in part } \\
\text { regression relationships }\end{array}$ & $\begin{array}{l}\text { Urban system change, } \\
\text { urban sustainable de- } \\
\text { velopment and urbani- } \\
\text { zation and } \\
\text { eco-environment ele- } \\
\text { ment coupling }\end{array}$ \\
\hline $\begin{array}{l}\text { Artificial } \\
\text { neural } \\
\text { network }\end{array}$ & $\begin{array}{l}\text { Artificial intelli- } \\
\text { gence }\end{array}$ & $\begin{array}{l}\text { A typical human brain } \\
\text { model with three advan- } \\
\text { tages: self-learning, asso- } \\
\text { ciative storage and } \\
\text { high-speed optimization }\end{array}$ & $\begin{array}{l}\text { Defective in learning, } \\
\text { causal explanation and } \\
\text { other aspects, espe- } \\
\text { cially in dealing with } \\
\text { system uncertainty }\end{array}$ & $\begin{array}{l}\text { Urban land expansion, } \\
\text { environmental change, } \\
\text { and resources demand }\end{array}$ \\
\hline $\begin{array}{l}\text { Bayesian } \\
\text { networks }\end{array}$ & $\begin{array}{l}\text { Artificial intelli- } \\
\text { gence, probability } \\
\text { theory, statistics } \\
\text { and graph theory }\end{array}$ & $\begin{array}{l}\text { Good at causal and diag- } \\
\text { nostic reasoning, as em- } \\
\text { pirical data can be in- } \\
\text { complete }\end{array}$ & $\begin{array}{l}\text { Difficult to deal with the } \\
\text { large number of nodes } \\
\text { and the learning ability } \\
\text { is less than for ANN }\end{array}$ & $\begin{array}{l}\text { Identification of urban } \\
\text { ecological vulnerability } \\
\text { and demand for re- } \\
\text { sources }\end{array}$ \\
\hline CLUE-S & $\begin{array}{l}\text { LUCC, systems } \\
\text { science and com- } \\
\text { puter simulation }\end{array}$ & $\begin{array}{l}\text { Good at dealing with } \\
\text { different spatial scales } \\
\text { based on empirical data }\end{array}$ & $\begin{array}{l}\text { Focus on local equilib- } \\
\text { rium analysis }\end{array}$ & $\begin{array}{l}\text { Land use allocation on } \\
\text { multiple spatial scales }\end{array}$ \\
\hline $\begin{array}{l}\text { Cellular } \\
\text { automata }\end{array}$ & $\begin{array}{l}\text { LUCC, systems } \\
\text { science and com- } \\
\text { puter simulation }\end{array}$ & $\begin{array}{l}\text { Simplifies complex } \\
\text { problems by bottom-up } \\
\text { modeling and can simu- } \\
\text { late complex discrete } \\
\text { systems }\end{array}$ & $\begin{array}{l}\text { Difficult to solve the } \\
\text { problem of spatial } \\
\text { heterogeneity and lacks } \\
\text { explanation of the } \\
\text { mechanism }\end{array}$ & $\begin{array}{l}\text { Urban sprawl and land } \\
\text { use change }\end{array}$ \\
\hline $\begin{array}{l}\text { Multi-agent } \\
\text { system }\end{array}$ & $\begin{array}{l}\text { Artificial intelli- } \\
\text { gence and com- } \\
\text { plexity science }\end{array}$ & $\begin{array}{l}\text { Compensates for the } \\
\text { neglect of policy factors } \\
\text { and explains land use } \\
\text { change processes }\end{array}$ & $\begin{array}{l}\text { Research space is ab- } \\
\text { stracted as homogene- } \\
\text { ous and model valida- } \\
\text { tion is difficult }\end{array}$ & $\begin{array}{l}\text { Policy-driven urban } \\
\text { sprawl and land use } \\
\text { change }\end{array}$ \\
\hline
\end{tabular}

Dynamic simulation methods have many shortcomings: (1) Combining or integrating methodologies is difficult and it is hard to simulate the multi-scenario, multi-scale, multi-factor and multi-agent. (2) Many research results are limited to qualitative analysis because of a lack of systematic quantitative analysis and simulation methods for cross-scale coupling. (3) Because the development of interactive decision support systems is in the feasibility stage, there is a lack of developed products and few technical services in planning 
departments. (4) It is difficult to obtain urbanization and eco-environment coupling data, especially primary data.

We must unify simulation technology and encourage data sharing, develop linked dynamic simulation technology and interactive decision support systems, and build databases that support big data. These activities will accelerate the transition from theoretical research to practical dynamic simulation and thus provide decision support for regional sustainable urbanization.

\section{Progress in applications of dynamic simulation of urbanization and eco- environment coupling}

The case studying areas of different types, multiple elements, telecoupling and cross-scaling are involved in the applications; therefore, they determine how to represent regional differences, identify the main control elements, and emphasize cross-scale coupling.

\subsection{Different types of areas}

There have been many studies at national and provincial scales. For example, Roberts (1994) argued that the expansion of urban populations led to the environmental crisis, low rural productivity, wealth concentration, and disruption of urban zoning in developing countries. Liu et al. (2005) studied the processes of urbanization and eco-environment coupling in China and found that the stress of urbanization on the eco-environment and the constraints of the eco-environment on urbanization are coterminous. Zhang and Jiao (2015) considered that urbanization and eco-environment coupling in China is at a running-in stage; that coordination in the eastern region is better than in the central and western regions. Tan et al. (2015) quantified the changing spatio-temporal processes of urbanization and eco-environment coupling in Jilin province from 2000 to 2012 and found urbanization and eco-environmental changes were highly coordinated because of the implementation of the Northeast Area Revitalization Plan. Spatial differences exist among areas of urbanization and areas of the eco-environment because of different geographical features suggest that different types of area should be analyzed separately.

(1) Urban area. Two methods are commonly used in studying urban areas. The first method is to study individual cities. Hayashi et al. (1994) compared London, Tokyo, Nagoya and Bangkok and showed that an urban transport system leads to increased energy consumption and environmental degradation. Wilby and Perry (2006) used London as an example to show that urban green space planning can reduce the effects of urbanization on reducing biodiversity and environmental quality. Zhang et al. (2015) used the ARDL model to investigate the relationship between urbanization and carbon emissions in Beijing from 1980 to 2013 and found that urbanization had a significant impact on carbon emissions in both the short and long term. He et al. (2017) simulated urbanization and eco-environment coupling processes in Shanghai from 1980 to 2013 and found that it could be represented in an S-shaped curve.

The second method is to study urban agglomerations. An urban agglomeration is an important region which competes internationally in terms of trade and industry, while it faces severe resource and environmental constraints (Fang et al., 2017). Wang et al. (2014) used 
an interactive coercing model (ICM) followed by a dynamic coupling coordination degree model (DCCDM) to represent the relationship between urbanization and eco-environment in the Beijing-Tianjin-Hebei urban agglomeration; they found that it could be represented in an inverted U-shaped curve. Zhao et al. (2016) found that urbanization and eco-environment coupling in the Yangtze River Delta urban agglomeration from the improved environmental Kuznets curve model (EKC) with the dynamic coordination coupling degree model (CCD) could be represented in an S-shaped curve.

(2) River basin. In the area of a river basin, water resources, the hydrologic environment and water ecology all bear importantly on the economic and social system; therefore, the interaction between the hydrological system and the urbanization pattern is significant (Yuan et al., 2012). Fang and Bao (2004) simulated the development of the water-ecology-economy complex system in the Heihe River Basin and suggested the WEE scheme to manage coordinated development of the basin. Zhang et al. (2010) simulated the collaborative development of the human-land system in the Weihe River basin from 1996 to 2006 and found that it conformed to the S-shaped curve. Yang and Tong (2013) simulated the spatio-temporal coupling processes of the economy-water environment system in the Songhua River Basin from 1991 to 2010 and found that they showed a nonlinear increasing trend. Guo and Xu (2013) simulated the interactive coupling processes of urbanization and eco-environment in the Huaihe River basin using fuzzy matter-element analysis and found that they had a good synergistic effect. Du (2014) simulated the spatio-temporal coupling of water resources and the economy in Dongting Lake basin from 2002 to 2012 using the gray relational degree model and inferred that they were in the coordination stage.

(3) Arid area. An arid area is ecologically fragile; therefore, urbanization is strongly constrained by resources and the eco-environment. Qiao et al. (2006) investigated the function, trajectory, type and stage of urbanization and eco-environment coupling in an arid area, and found that it was a dynamic process with interactive stress between the parameters. Abdirahman et al. (2010) investigated the sustainability of the water-economic-social system in the Qiemo Oasis. Dong et al. (2013) used a VAR model to simulate the spatio-temporal processes of urbanization and water-land resources coupling in an oasis on the northern slope of Tianshan Mountains and found that urbanization leads to increased water consumption. Tang et al. (2014) analyzed the response relationship between urbanization and water resources in Zhangye and found that the processes move towards synergy.

(4) Mountainous area. Mountains are usually categorized as restricted or forbidden development zones in the major function-oriented zoning categories, exemplifying the dilemma between development and protection. Wang et al. (2014) simulated the spatio-temporal development of vegetation cover over hilly terrain in southern China from 2000 to 2010 and found that human activities and climate jointly influenced the change of NDVI. Wang et al. (2016) quantified the ecological risk index for Jinlinwan in Qujing and found that the layered gradient mode of development would increase the ecological risk. Wen et al. (2016) quantified the vulnerability of a social-ecological system (SES) in Qinling Mountains from 1997 to 2013 and created a plan to control development for many adaptation targets.

\subsection{Multi-element coupling and control}

The urbanization and eco-environment coupling are considered as a complex unity of many 
elements by us via systems science and complexity science. Zhang and Jiao (2015) divided the urbanization system into population, space, economy and society; the ecosystem was divided into environmental pollution and environmental treatment. Zhang et al. (2016) divided the urbanization system into urbanization level and urbanization efficiency; the eco-environment system was divided into eco-environment level, eco-environment pressure and eco-environment protection using an efficiency-level theory. The process of urbanization and eco-environment coupling can be regulated by identifying the key controlling factors from the analysis of multi-element coupling and control.

(1) Water resources are important influence factors on urbanization. The demand for water resources from urbanization is direct and necessary; however, the population size and the scale of production should be maintained within the carrying capacity of available water resources. The hydrological system also affects urbanization patterns and processes (Bao and Chen, 2015). Varis and Somlyody (1997) quantified the contribution of water resources to urbanization to investigate the driving forces of urbanization in the Third World; therefore, identified water is a key variable in the process. Srinivasan et al. (2013) examined the vulnerability of the urban human-water system in a developing country; they took Chennai as an example, and found that the system dynamics, variability and spatial dependence were the most influenced vulnerability. Mcdonald et al. (2014) found that $78 \pm 3 \%$ of the total global surface water went to big cities; however, the demand for water resources was still significant. In arid areas, the influence of water resources on urbanization is more decisive (Zhang et al., 2012).

(2) Land resources also constrain urbanization. Current studies tend to regard urbanization as requisitioning the landscape; it is mainly manifested in the transformation from natural, rural and other regional landscapes to urban landscapes, accompanied by dynamic changes in land use types and landscape fragmentation (Antrop, 2004; Weng, 2007). Land resources provide space and resource support for urbanization; therefore, a lag in land development will lead to low land use efficiency and adversely affect urbanization. In China, coordination between population urbanization and land urbanization has become a hotly-debated topic. Li (2013) explained that the reason why China's population urbanization lags behind its land urbanization is that, there is the joint effect of the rapid expansion of land use, increasingly available land finance and control of household registration. Lv et al. (2016) quantified coordination between population urbanization and land urbanization in Nanchang from 2002 to 2011 and found that population lag has replaced land lag.

(3) Some researchers have investigated landform as a stressor of urbanization. Over $50 \%$ of Chinese cities and towns are situated in mountainous areas; therefore, mountain urbanization is a major concern (Li, 1998). Topography, geomorphology and related geological events or disasters are important stressors of mountain urbanization when compared with plains, basins and coastal zones. The Three Gorges Project provides an example. Zhang et al. (2011) analyzed the spatio-temporal changes in urbanization patterns over the Three Gorges Reservoir area before and after the project; they concluded that the Three Gorges Project destroyed the integrity of existing urban space, but created a balanced urbanization pattern in the region. Cao and Xiao (2013) argued that urban functions and forms and the organization and structure of road networks need to follow the mountain landform. Han and Zhang (2017) used the Entropy-TOPSIS model to identify the coupling relationship between ur- 
banization and geological disasters in China and found that they tended gradually to coordinate.

(4) Some researchers have created comprehensive bearing capacity quantification models that incorporate the main drivers. Zhang et al. (2016) quantified the coupling relationship between urbanization and eco-environment carrying capacity in Chongqing from 2000 to 2012 and concluded that urbanization led to increased pressure on the regional eco-environment. Liu et al. (2016) quantified the response relationship among natural resources and environment carrying capacity and urbanization in Shandong Province from 1991 to 2014; they found that it transitioned from positive to negative. Chi et al. (2017) studied the natural resources and environment carrying capacity for urbanization in the Miaodao islands and concluded that a critical state had been reached.

\subsection{Local coupling and telecoupling}

The introduction of a telecoupling framework extends the coupling scale into many dimensions such as time, space and organization. Eakin et al. (2014) examined the external effects of telecoupling between society and ecology on a land system. Using the teleconnection framework, Deines et al. (2016) analyzed the sustainability of the teleconnection of an overseas water source to the urban water supply in Beijing and found that it reduced risk to the water supply. Lenschow et al. (2016) argued that teleconnection between social ecosystems brings risks to globalization and that global governance should be strengthened. Quan et al. (2016) quantified that the ecological risks of inter-basin water diversion using the IBWTPS model and concluded that the best way to strengthen ecological security is to share information. Hulina et al. (2017) studied the effects of global population migration on biodiversity and found that they cascaded into other systems such as tourism, land use, and climate change. Fang and Ren (2017) simulated dynamic changes in locally coupled and telecoupled elements in the Beijing-Tianjin-Hebei urban agglomeration from 1980 to 2015 , using the framework of urban energy metabolism, to provide a scientific basis for coordinated development.

Recently, cross-regional economic cooperation, cultural exchanges, trade, commuting and pollution have become increasingly prominent concerns; therefore, they lead the government, business and public sectors to pay more attention to regional collaborative development. $\mathrm{Li}$ and Liu (2014) analyzed the coordinated development processes of the regional economy in China from 1992 to 2011, using the Haken model, and found that regional economic relations and industrial categories replaced regional comparative advantages as economic drivers. Bo and Chen (2015) argued that there were three obstacles to the coordinated development of the Beijing-Tianjin-Hebei region: the reduction in industrial diversity, a huge development gap, and lack of governance processes. Fang (2017) investigated the regularity of coordinated development in the Beijing-Tianjin-Hebei urban agglomeration and found that it was a nonlinear increasing spiral process.

\subsection{Applications review}

The application of the results of simulation is mainly focused on three components: multiple-case regions; multiple elements, local coupling, and telecoupling; and regional synergy. (1) The types of areas used in cases are diversified, and much attention is given to urban 
agglomerations. The areas used as cases include urbanization areas, river basins, arid regions and mountainous areas. Research covers theoretical research, empirical demonstration and observation, process analysis, and decision support for urban agglomerations provided by urbanization and eco-environment coupling. (2) The trend for unifying multiple elements is significant; therefore, the main driving elements have been comprehensively identified. As systems science and complexity science continue to develop and their use grows, increasing numbers of studies have shown that urbanization and eco-environment coupling is a complex unification of many factors. (3) Local coupling and telecoupling are both of interest. International research has shifted to spatial scales, while domestic Chinese research has paid more attention to regional collaborative development.

We also found some drawbacks. (1) The identification of the main driving elements ignores system dynamics. Many studies only consider spatial differences, but it is necessary to understand regularity, trends, and dynamics. (2) The complete chain of relationships and processes in urbanization and eco-environment coupling has not been identified. Fragmented applications (those that consider some, not all) do not fully reveal the complete chain of relationships. (3) Telecoupling simulation focuses on micro cases such as cross-border tourism, energy trading, urban security, ecological risk, and species invasion; however, telecoupling simulation is not quantified, lacks systematic unity and is disconnected from regional application.

In the future, we must take national strategy and responses to global change as goals, and show the local coupling and telecoupling relationships identified by the simulations in key areas such as urban agglomeration. On the other hand, we must also emphasize the dynamic nature of the driving elements, as well as the scientific basis of the coordination strategy, and thus promote the application of research into aspects of systems behavior such as inflection point identification, threshold definition, dynamic simulation and monitoring, and risk warning and response.

\section{Review and prospects}

There is a complex nonlinear interactive coupling between urbanization and the eco-environment. Science is the key to accurately simulating this complex dynamic relation. Systems science and cross-scale coupling theory allow us to define the coupled urbanization and eco-environment system as an open complex giant system with multiple feedback loops.

We reviewed the current literature for dynamic simulation of urbanization and eco-environment coupling. (1) As dynamic simulation becomes more popular, theory and analysis have been improved. Studies of urbanization and eco-environment coupling refer to and improve the environmental Kuznets curve (EKC), showing relationships that can be represented by inverted U-shaped or S-shaped curves. (2) Dynamic simulation technologies have become more diversified, refined, intelligent, and integrated. Improved simulation technologies based on SD, artificial intelligence and land use and land cover change models are being rapidly developed, leading to increased use and development of simulation technology for unified systems. (3) Current simulations are used mainly for three aspects: multiple regions and multiple elements, local coupling and telecoupling, and regional synergy. However, we also found some shortcomings: (1) The development and unification of basic theories are inadequate; (2) The methods of unifying separate systems and transferring data 
among them are not as advanced as they might be; and (3) The coupling relations and the dynamic characteristics of the main driving elements have not been fully identified. Moreover, telecoupling simulation does not quantify and is not systemically unified; therefore, it cannot be used to model spatial synergy transference.

In the future, we should promote the development of complex systems theory, cross-scale coupling theory and other new theories; therefore, the benefits of cross-disciplinary research into the unified human-nature system should be realized; thus we should form a multi-disciplinary research network for urbanization and eco-environment coupling. We must also promote the unification of simulation technology and data transfer, develop unified dynamic simulation technology and interactive decision support systems, and build database support for big data. Eventually, we should identify the local coupling and telecoupling relationships; thus we promote the application of research into topics such as inflection point identification, threshold definition, dynamic simulation and monitoring, and risk identification and response.

\section{References}

Abdirahman H, Wahap H, Bian Z F, 2010. The quantitative analysis of coupling system sustainable development of oasis water resources-ecological environment-economic society. Journal of Arid Land Resources and Environment, 24(4): 26-31. (in Chinese)

Allen T F H, Starr T B, 1982. Hierarchy: Perspectives for Ecological Complexity. Chicago: University of Chicago Press.

Antrop M, 2004. Landscape change and the urbanization process in Europe. Landscape and Urban Planning, 67(1-4): 9-26.

Arrow K J, Dasgupta P, Mäler K, 2003. Evaluating projects and assessing sustainable development in imperfect economies. Environmental \& Resource Economics, 26(4): 647-685.

Balbi S, Villa F, Mojtahed V et al., 2016. A spatial Bayesian network model to assess the benefits of early warning for urban flood risk to people. Natural Hazards \& Earth System Sciences, 16(6): 1323-1337.

Bao C, Chen X J, 2015. The driving effects of urbanization on economic growth and water use change in China: A provincial-level analysis in 1997-2011. Journal of Geographical Sciences, 25(5): 530-544.

Bartlett R V, 2010. Protecting the ozone layer: Science and strategy. Journal of Politics, 67(1): 285-286.

Bo W G, Chen F, 2015. The coordinated development among Beijing, Tianjin and Hebei: Challenges and predicaments. Nankai Journal: Philosophy, Literature and Social Science Edition, (1): 110-118. (in Chinese)

Cai M, Yin Y, Xie M, 2009. Prediction of hourly air pollutant concentrations near urban arterials using artificial neural network approach. Transportation Research Part D: Transport \& Environment, 14(1): 32-41.

Cao K, Xiao J, 2013. Road system planning based on topographic analysis: Case studies of mountainous cities in southwest China. Mountain Research, 31(4): 473-481. (in Chinese)

Chen H, Liang X Y, Gao H D et al., 2008. A review on multi-agent system for the simulation of land-use and land-cover change. Journal of Natural Resources, 23(2): 345-352.

Chen L D, Sun R H, Liu H L, 2013. Eco-environmental effects of urban landscape pattern changes: Progresses, problems, and perspectives. Acta Ecologica Sinica, 33(4): 1042-1050. (in Chinese)

Chen L D, Zhou W Q, Han L J et al., 2016. Developing key technologies for establishing ecological security patterns at the Beijing-Tianjin-Hebei urban megaregion. Acta Ecologica Sinica, 36(22): 7125-7129. (in Chinese)

Chi Y, Shi H H, Sun J K et al., 2017. Evaluation on island resources and environment carrying capacity under the background of urbanization. Journal of Natural Resources, 32(8): 1374-1384. (in Chinese)

Cui X G, Fang C L, Liu H M et al., 2019. Assessing sustainability of urbanization by a coordinated development index for an Urbanization-Resources-Environment complex system: A case study of Jing-Jin-Ji region, China. Ecological Indicators, 96: 383-391.

Cui X G, Wang C X, Wang X Q, 2016. Research on optimizing the new path of metropolises' spatial structure under the fog and haze crisis. Shanghai Journal of Economics, (1): 13-21. (in Chinese) 
Deines J M, Liu X, Liu J, 2016. Telecoupling in urban water systems: An examination of Beijing's imported water supply. Water International, 41(2): 251-270.

Deng X Z, Lin Y Z, Huang H Q, 2009. Simulation of land system dynamics: A review. Chinese Journal of Ecology, 28(10): 2123-2129. (in Chinese)

Dong C Y, 2011. Analyzing the meaning of order parameter and slaving principle for wholism. Chinese Journal of Systems Science, 19(2): 17-21. (in Chinese)

Dong W, Yang Y, Zhang Y F, 2013. Coupling effect and spatio-temporal differentiation between oasis city development and water-land resources. Resources Science, 35(7): 1355-1362. (in Chinese)

Du X H, Zhang T, 2014. The simulation to coupling development between water resource \& environment and socio-economic system: Dongting Lake ecological economic zone as an example. Economic Geography, 34(8): 151-155. (in Chinese)

Eakin H, Defries R, Kerr S et al., 2014. Significance of Telecoupling for Exploration of Land-Use Change. Cambridge: MIT Press.

Entwisle B, Stern P C, 2005. Population, Land Use, and Environment. Washinton, D. C.: National Academies Press.

Fan J, 2014. Frontier approach of the sustainable process and pattern of human-environment system. Acta Geographica Sinica, 69(8): 1060-1068. (in Chinese)

Fang B L, Tan Y, Li C B et al., 2016. Energy sustainability under the framework of telecoupling. Energy, 106: 253-259.

Fang C L, 1989. Dissipative structure theory and geography system. Arid Land Geography, 12(3): 53-58. (in Chinese)

Fang C L, 2009. Report on China's Urbanization and the Resources and Environment Security. Beijing: Science Press. (in Chinese)

Fang C L, 2017. Theoretical foundation and patterns of coordinated development of the Beijing-Tianjin-Hebei urban agglomeration. Progress in Geography, 36(1): 15-24. (in Chinese)

Fang C L, Bao C, 2004. The coupling model of water-ecology-economy coordinated development and its application in Heihe River Basin. Acta Geographica Sinica, 59(5): 781-790. (in Chinese)

Fang C L, Liu H M, Li G D, 2016. International progress and evaluation on interactive coupling effects between urbanization and the eco-environment. Journal of Geographical Sciences, 26(8): 1081-1116.

Fang C L, Ren Y F, 2017. Analysis of emergy-based metabolic efficiency and environmental pressure on the local coupling and telecoupling between urbanization and the eco-environment in the Beijing-Tianjin-Hebei urban agglomeration. Science China Earth Sciences, 47(7): 833-846. (in Chinese)

Fang C L, Song J T, Lin X Q et al., 2010. Theory and Practice on the Sustainable Development of China's Urban Agglomeration. Beijing: Science Press. (in Chinese)

Fang C L, Yang Y M, 2006. Basic laws of the interactive coupling system of urbanization and ecological environment. Arid Land Geography, 29(1): 1-8. (in Chinese)

Fang C L, Zhou C H, Gu C L et al., 2017. A proposal for the theoretical analysis of the interactive coupled effects between urbanization and urbanization and the eco-environment in mega-urban agglomerations. Journal of Geographical Sciences, 27(12): 1431-1449.

Fang W, An H, Li H et al., 2017. Accessing on the sustainability of urban ecological-economic systems by means of a coupled emergy and system dynamics model: A case study of Beijing. Energy Policy, 100: 326-337.

Feng Y Y, Chen S Q, Zhang L X, 2013. System dynamics modeling for urban energy consumption and $\mathrm{CO}_{2}$ emissions: A case study of Beijing, China. Ecological Modelling, 252(1755): 44-52.

Froelich W, 2015. Forecasting daily urban water semand using Dynamic Gaussian Bayesian Network. Communications in Computer \& Information Science, 521: 333-342.

Fu B J, 2017. Geography: From knowledge, science to decision making support. Acta Geographica Sinica, 72(11): 1923-1932. (in Chinese)

Grimm N B, Faeth S H, Golubiewski N E et al., 2008. Global change and the ecology of cities. Science, 319(5864): 756-760.

Gu C L, Zhang Y, Zhai W et al., 2016. Progress in urban and regional quantitative research. Progress in Geography, 35(12): 1433-1446. (in Chinese)

Guerrero C N, Schwarz P, Slinger J H, 2016. A recent overview of the integration of system dynamics and 
agent-based modelling and simulation//Proceedings of the 34th International Conference of the System Dynamics Society.

Gunderson L H, Holling C S, Gunderson L H et al., 2004. Panarchy: Understanding transformations in human and natural systems. Ecological Economics, 49(4): 488-491.

Guo Y T, Xu J G, 2013. Coupling coordination measurement of urbanization and eco-environment system in Huaihe River Basin of China based on fuzzy matter element theory. Chinese Journal of Applied Ecology, 24(5): 1244-1252. (in Chinese)

Han X, Zhang N, 2017. Analysis on coupling coordination degree between urbanization and geo-hazards in China based on TOPSIS. Hydrogeology \& Engineering Geology, 44(2): 167-171. (in Chinese)

Hayashi Y, Suparat R, Mackett R et al., 1994. Urbanization, motorization and the environment nexus: An international comparative study of London, Tokyo, Nagoya and Bangkok. Xenotransplantation, 21(3): 254-266.

Haykin S S, 2009. Neural Networks and Learning Machines. Uper Saddle River: Pearson Prentice-Hall.

He J, Wang S, Liu Y et al., 2017. Examining the relationship between urbanization and the eco-environment using a coupling analysis: Case study of Shanghai, China. Ecological Indicators, 77: 185-193.

Holling C S, 1973. Resilience and stability of ecological systems. Annual Review of Ecology \& Systematics, 4(1): $1-23$.

$\mathrm{Hu}$ J, Sun J H, 2017. Early classification warning for regional energy security exogenous sources based on FI-GA-NN model. Resources Science, 39(6): 1048-1058. (in Chinese)

Huang J C, Fang C L, 2003. Analysis of coupling mechanism and rules between urbanization and eco-environment. Geographical Research, 22(2): 211-220. (in Chinese)

Huang Y P, 2013. Survey on Bayesian network development and application. Transactions of Beijing Institute of Technology, 33(12): 1211-1219. (in Chinese)

Hulina J, Bocetti C, Iii H C et al., 2017. Telecoupling framework for research on migratory species in the Anthropocene. Elementa: Science of the Anthropocene, 5: 5-27.

IGBP, 2001. Reberberation of change. IGBP Science Series, 4: 15-18.

Ii B L T, Matson P A, Mccarthy J J et al., 2003. Science and technology for sustainable development special feature: Illustrating the coupled human-environment system for vulnerability analysis: Three case studies. Proceedings of the National Academy of Sciences of the United States of America, 100(14): 8080.

IPCC, 2007. Climate Change 2007: The Physical Science Basis, Contribution of Working Group I to the Fourth Assessment Report of the Intergovernmental Panel on Climate Change. Cambridge: Cambridge University Press.

Jabareen Y, 2015. The Risk City Resilience Trajectory. Berlin: Springer Netherlands.

Kates R W, Clark W C, Corell R et al., 2001. Environment and development: Sustainability science. Science, 292(5571): 641-642.

Lenschow A, Newig J, Challies E, 2016. Globalization's limits to the environmental state? Integrating telecoupling into global environmental governance. Environmental Politics, 25(1): 136-159.

Li H P, 1998. The philosophical debate in mountainous city planning. City Planning Review, (3): 52-53. (in Chinese)

Li L, Liu Y, 2014. The driving forces of regional economic synergistic development in China: Empirical study by stages based on Haken model. Geographical Research, 33(9): 1603-1616. (in Chinese)

Li S C, Wang Y, Cai Y L, 2010. The paradigm transformation of geography from the perspective of complexity sciences. Acta Geographica Sinica, 65(11): 1315-1324. (in Chinese)

Li S C, Zhao Z Q, Wang Y L, 2009. Urbanization process and effects of natural resource and environment in China: Research trends and future directions. Progress in Geography, 28(1): 63-70. (in Chinese)

Li S H, Zhang J, 2015. Review of Bayesian networks structure learning. Application Research of Computers, 32(3): 641-646. (in Chinese)

Li X Y, Yang Y, Liu Y, 2016. Research progress in man-land relationship evolution and its resource-environment base in China. Acta Geographica Sinica, 71(12): 2067-2088. (in Chinese)

Li Y F, Zhu X D, Ma Y, 2008. Urbanization, global environmental change and IHDP. Environment and Sustainable Development, (6): 42-44. (in Chinese)

Li Z L, 2013. A study on the causes of population urbanization laging behind land urbanization. China Population, Resources and Environment, 23(11): 94-101. (in Chinese) 
Liu C L, Yan Q, Luo J, 2013. System dynamics simulation on the coupling of economy resources environment system in Wuhan Metropolitan Region. Geographical Research, 32(5): 857-869. (in Chinese)

Liu D S, 2002. Global changes sustainability science. Earth Science Frontiers, 9(1): 1-9. (in Chinese)

Liu H M, Fang C L, Mao H Y et al., 2016. Mechanism of oasis urbanization: A theoretical framework based on complexity theory. Geographical Research, 35(2): 242-255. (in Chinese)

Liu H M, Shi P J, Yang X M et al., 2014. Self-organization evolution simulation and empirical study of human-water system. Journal of Natural Resources, 29(4): 709-718. (in Chinese)

Liu J G, Daily G C, Ehrlich P R et al., 2003. Effects of household dynamics on resource consumption and biodiversity. Nature, 421(6922): 530-533.

Liu J G, Diamond J, 2005. China's environment in a globalizing world. Nature, 435(7046): 1179-1186.

Liu J G, Dietz T, Carpenter S R et al., 2007. Complexity of coupled human and natural systems. Science, 317(5844): 1513-1516.

Liu J G, Dietz T, Carpenter S R et al., 2007. Coupled human and natural systems. Ambio, 36(8): 639-649.

Liu J G, Hull V, Batistella M et al., 2013. Framing sustainability in a telecoupled world. Ecology \& Society, 18(2): 344-365.

Liu K, Ren J L, Zhang L J et al., 2016. Urbanization's resource environmental bearing capacity response from man-land relationship perspective: Take Shandong Province as an example. Economic Geography, 36(9): 77-84. (in Chinese)

Liu X P, Tang Y M, Zheng L P, 2008. Survey of complex system and complex system simulation. Journal of System Simulation, 20(23): 6303-6315. (in Chinese)

Liu Y B, Li R D, Song X F, 2005. Grey associative analysis of regional urbanization and eco-environment coupling in China. Acta Geographica Sinica, 60(2): 237-247. (in Chinese)

Liu Y Y, Wang S J, 2015. Coupling coordinative degree and interactive coercing relationship between urbanization and eco-environment in Pearl River Delta. Human Geography, 30(3): 64-71. (in Chinese)

Liu Z, He C, Zhou Y et al., 2014. How much of the world's land has been urbanized, really? A hierarchical framework for avoiding confusion. Landscape Ecology, 29(5): 763-771.

Lu D D, Guo L X, 1998. Man-earth areal system - The core of geographical study: On the geographical thoughts and academic contributions of academician Wu Chuanjun. Acta Geographica Sinica, 53(2): 3-11. (in Chinese)

Lv T G, Wu C F, Li H Y et al., 2016. The coordination and its optimization about population and land of urbanization: A case study of Nanchang City. Scientia Geographica Sinica, 36(2): 239-246. (in Chinese)

Ma S J, Wang R S, 1984. The social-economic-natural complex ecosystem. Acta Ecologica Sinica, 4(1): 1-9. (in Chinese)

Mcdonald R I, Weber K, Padowski J et al., 2014. Water on an urban planet: Urbanization and the reach of urban water infrastructure. Global Environmental Change, 27(1): 96-105.

Meadows D H, Meadows D L, Randers J et al., 1972. The Limits to Growth. New York: Universe Books.

Millennium Ecosystem Assessment (MEA), 2005. Ecosystems and Human Well-Being: Synthesis. Washinton, D. C.: Island Press.

O'meara M, 1999. Reinventing cities for people and the planet//Worldwatch Paper. Washington, DC: Worldwatch Institute.

Ostrom E, 2009. A General Framework for analyzing sustainability of social-ecological systems. Science, 325(5939): 419-422.

Qian X S, Yu J Y, Dai R W, 1990. A new discipline of science: The study of open complex giant system and its methodology. Chinese Journal of Nature, (1): 3-10. (in Chinese)

Qiao B, Fang C L, Huang J C, 2006. The coupling law and its validation of the interaction between urbanization and eco-environment in arid area. Acta Ecologica Sinica, 26(7): 2183-2190. (in Chinese)

Quan Y, Wang C, Yan Y et al., 2016. Impact of inter-basin water transfer projects on regional ecological security from a telecoupling perspective. Sustainability, 8(2): 162-173.

Reid W V, Chen D, Goldfarb L et al., 2010. Earth system science for global sustainability: Grand challenges. Science, 330(6006): 916-917.

Rignot E, Kanagaratnam P, 2006. Changes in the velocity structure of the Greenland Ice Sheet. Science, 311(5763): 986-990.

Roberts B R, 1994. Urbanization and the environment in developing countries//Latin America in Comparative 
Perspective. Population and Environment: Rethinking the Debate. Boulder: Westview Press.

Sanchez-Rodriguez R, Seto K, Simon D et al., 2014. Science Plan: Urbanization and Global Environmental Change. Bonn: International Human Dimensions Programme on Global Environmental Change.

Schneider A, Mertes C M, Tatem A J et al., 2015. A new urban landscape in East-Southeast Asia, 2000-2010. Environmental Research Letters, 10(3): 1-14.

Song C Q, Cheng C X, Shi P J, 2018. Geography complexity: New connotations of geography in the new era. Acta Geographica Sinica, 73(7): 1204-1213. (in Chinese)

Srinivasan, Veena, Seto et al., 2013. The impact of urbanization on water vulnerability: A coupled human-environment system approach for Chennai, India. Global Environmental Change, 23(1): 229-239.

Sta P, Cadenasso M L, Grove J M, 2005. Biocomplexity in coupled natural-human systems: A multidimensional framework. Ecosystems, 8(3): 225-232.

Sun H P, Huang Z F, Xu D D et al., 2017. The spatial characteristics and drive mechanism of coupling relationship between urbanization and eco-environment in the Pan Yangtze River Delta. Economic Geography, 37(2): 163-170. (in Chinese)

Sun Y Z, Lu C X, Xie G D et al., 2015. Water footprint in Beijing. Chinese Journal of Ecology, 34(2): 524-531. (in Chinese)

Sven F, Margreth K, Thomas G, 2017. Editorial to the special issue on resilience and vulnerability assessments in natural hazard and risk analysis. Natural Hazard and Earth System Sciences, 17(7): 1203-1206.

Tan J T, Zhang P Y, Li J et al., 2015. Spatial-temporal evolution characteristic of coordination between urbanization and eco-environment in Jilin Province, Northeast China. Chinese Journal of Applied Ecology, 26(12): 3827-3834. (in Chinese)

Tang H J, Wu W B, Yang P et al., 2009. Recent progresses of land use and land cover change (LUCC) models. Acta Geographica Sinica, 64(4): 456-468. (in Chinese)

Tang Z P, Zhang J, Liu W D et al., 2010. A comparative study on the differences of physical process and human process modeling. Acta Geographica Sinica, 65(12): 1581-1590. (in Chinese)

Tang Z Q, Cao J, Dang J, 2014. Interaction between urbanization and eco-environment in arid area of northwest China with constrained water resources: A case of Zhangye City. Arid Land Geography, 37(3): 520-531. (in Chinese)

Tian D S, Fu B T, Lv Y P et al., 2016. Effect of regional land-use change on soil organic carbon storage based on SD and CLUE-s model. Resources and Environment in the Yangtze Basin, 25(4): 613-620. (in Chinese)

Tratalos J, Fuller R A, Warren P H et al., 2007. Urban form, biodiversity potential and ecosystem services. Landscape \& Urban Planning, 83(4): 308-317.

Varis O, Somlyódy, 1997. Global urbanization and urban water: Can sustainability be afforded? Water Science \& Technology, 35(9): 21-32.

Walker B, Carpenter S R, Anderies J M et al., 2002. Resilience management in social-ecological systems: A working hypothesis for a participatory approach. Ecology \& Society, 6(1): 840-842.

Wan L, Zhang Y, Qi S et al., 2016. A study of regional sustainable development based on GIS/RS and SD model: Case of Hadaqi industrial corridor. Journal of Cleaner Production, 142: 654-662.

Wang C X, 2017. Structural Interpretation and Development Transformation: A Comprehensive Analysis on Chinese Urbanization. Beijing: People's Publishing House. (in Chinese)

Wang C X, Cui X G, Wang X Q, 2014. Analysis of Chinese "urban agglomerations disease" phenomenon under new urbanization background. Urban Development Studies, 21(10): 12-17. (in Chinese)

Wang J, Wang K L, Zhang M Y, 2014. Temporal-spatial variation in NDVI and drivers in hilly terrain of Southern China. Resources Science, 36(8): 1712-1723. (in Chinese)

Wang S J, Ma H, Zhao Y B, 2014. Exploring the relationship between urbanization and the eco-environment: A case study of Beijing-Tianjin-Hebei region. Ecological Indicators, 45: 171-183.

Wang W J, Ye L Y, Yang K et al., 2016. Ecological risk analysis of land use change on the gentle hillside mountain urbanization construction based on GIS. Research of Soil and Water Conservation, 23(6): 358-362. (in Chinese)

Wang X F, Wang Y J, Li Y F, 2013. Analysis and assessment model of environmental cumulative effects based on the integration of SD, CA and GIS methods and its application. Acta Scientiae Circumstantiae, 33(7): 2078-2086. (in Chinese) 
Wen X J, Yang X J, Wang Z Q, 2016. Assessment on the vulnerability of social-ecological systems in a mountainous city depending on multi-targets adaption. Geographical Research, 35(2): 299-312. (in Chinese)

Weng Y, 2007. Spatiotemporal changes of landscape pattern in response to urbanization. Landscape and Urban Planning, 81(4): 341-353.

Wilby R L, Perry G L W, 2006. Climate change, biodiversity and the urban environment: A critical review based on London, UK. Progress in Physical Geography, 30(1): 73-98.

Wu C J, 1991. The core of geographical study: Man-earth areal system. Economic Geography, 11(3): 1-6. (in Chinese)

Wu C J, 2008. Human-Earth Relations and Economic Layout. Beijing: Xueyuan Press. (in Chinese)

Xie L J, Zhou S H, Yan X P, 2010. A review of the recent researches on China's urbanization and global environmental change. Progress in Geography, 29(8): 952-960. (in Chinese)

Xie M X, Wang J Y, Chen K, 2016. Coordinated development analysis of the "Resources-EnvironmentEcology-Economy-Society" complex system in China. Sustainability, 8(6): 582-604.

Xu G H, Ge Q S, Gong P et al., 2013. Societal response to challenges of global change and human sustainable development. Chinese Science Bulletin, 58(21): 2100-2106. (in Chinese)

$\mathrm{Xu}$ J H, 2010. Geomodeling Methods. Beijing: Science Press. (in Chinese)

Yan D, Li A, Nan X et al., 2016. The study of urban land scenario simulation in mountain area based on modified Dyna-CLUE Model and SDM: A case study of the upper reaches of Minjiang River. Journal of Geo-Information Science, 18(4): 514-525. (in Chinese)

Yang L H, Tong L J, 2013. Dynamic coupling and spatial disparity of economic development and water environmental quality in Songhua River Basin of Jilin Province, Northeast China. Chinese Journal of Applied Ecology, 24(2): 503-510. (in Chinese)

Yuan X Y, Wu Y J, Li X M, 2012. Progress on unity coupling problems of watershed system dynamic model. Environmental Science and Management, 37(4): 68-72. (in Chinese)

Zeng R, Wei Y M, Fan Y et al., 2000. System analysis of harmonization development among population, resource, environment and economy. Systems Engineering: Theory \& Practice, (12): 1-6. (in Chinese)

Zhang J, Li T S, Wang W K, 2010. Quantitative analysis of coupling status of man-land relationship areal system in Weihe River Basin. Progress in Geography, 29(6): 733-739. (in Chinese)

Zhang L, Wu B F, Yuan C et al., 2011. Urban development and environment change before and after three gorges project construction in Three Gorges Reservoir Area. Resources and Environment in the Yangtze Basin, 20(3): 317-324. (in Chinese)

Zhang L W, Guo H P, 2006. Introduction to Bayesian Networks. Beijing: Science Press. (in Chinese)

Zhang R T, Jiao H F, 2015. Coupling and coordination between urbanization and ecological environment in China. Journal of Arid Land Resources and Environment, 29(7): 12-17. (in Chinese)

Zhang S W, Shi P J, Wang Z J, 2012. Analysis of coupling between urbanization and water resource and environment of inland river basin in arid region: A case study of Shiyang River Basin. Economic Geography, 32(8): 142-148. (in Chinese)

Zhang Y, Yang Q Y, Min J, 2016. An analysis of coupling between the bearing capacity of the ecological environment and the quality of new urbanization in Chongqing. Acta Geographica Sinica, 71(5): 817-828. (in Chinese)

Zhang Y J, Yi W C, Li B W, 2015. The Impact of urbanization on carbon emission: Empirical evidence in Beijing. Energy Procedia, 75: 2963-2968.

Zhao L, Yang J, Li C, 2016. System dynamic model for sustainable development of Wuhai City. Journal of Arid Land Resources and Environment, 24(12): 55-60. (in Chinese)

Zhao Y, Wang S, Zhou C, 2016. Understanding the relation between urbanization and the eco-environment in China's Yangtze River Delta using an improved EKC model and coupling analysis. Science of the Total Environment, 571: 862-875.

Zhong Y G, Jia X J, Qian Y et al., 2013. System Dynamics. 2nd ed. Beijing: Science Press. (in Chinese)

Zhou X, Han J, Meng X et al., 2014. Comprehensive analysis of spatio-temporal dynamic patterns and driving mechanisms of cropland loss in a rapidly urbanizing area. Resources Science, 36(6): 1191-1202. (in Chinese)

Zuo Q T, 2007. The embedded system dynamic model used to human-water system modeling. Journal of Natural Resources, 22(2): 268-274. (in Chinese) 